\title{
THE REGIONAL IMPACT OF LOCKDOWN FROM COVID-19 ON SMALL AND MEDIUM SIZE ENTERPRISES - BULGARIAN CASE
}

\author{
DOI: https://doi.org/10.18509/GBP210273k \\ UDC: $334.72 .012 .63 / .64-021.342:[616.98: 578.834(497.2)$ \\ 332.1.055.2 :334.72.012.63/.64-021.342:[616.98:578.834(497.2)
}

\author{
Nikolay Katsarski \\ Sofia University „St. Kliment Ohridski“, Faculty of Geology and Geography, Department \\ "Regional Development", Sofia, Bulgaria
}

\begin{abstract}
The whole world is faced with the biggest economic and financial crises in the world since the Great Depression. Small and medium-sized enterprises are important for the Europe union. The figures show that more than $90 \%$ of the enterprises are small and medium-sized. The methodological aspect which is used in analyses includes the statistical and financial approach. The figures are presenting entrepreneurial advantages from which some companies used to generate profit. Other aspect includes government policies and financial subvention to closed small and medium-sized enterprises.

The impact of lockdown from COVID-19 on small and medium enterprises in Bulgaria is significant. Most enterprises are closed or work with fewer employees. The crucial impact is on the services and production sectors. Services like the food and beverages and transport sectors are faced with bankruptcy. Even though they could not have the chance to switch on online orders business opportunities. The measures in production line sectors are not at the high level and it caused the lockdown. All of these aspects aimed to present the past, current, and future problems and their solving by financial subvention in regional aspect.
\end{abstract}

Keywords: small and medium enterprises, regional development, covid-19, lockdown

\section{INTRODUCTION}

Small and medium enterprises are significant for fulfilment of these niches which are not profitable for big businesses. SMEs form more than $95 \%$ of businesses in Europe union (EU). They cover more than $50 \%$ of employment worldwide and form up to $40 \%$ of gross domestic product in developing countries like Bulgaria. Figures estimated by World bank shows that about 600 million jobs will be need by 2030.[1] This put SMEs in the center for taking different employees and give them different roles and responsibilities which is not possible in big companies. They can accelerate high development in markets in which are working around 5-10 employees. Most problems for Bulgaria like developing country are less cash access, less formed financial reserves, little turnover, less investments in innovations, small enterprises. That is why COVID-19 have caught these enterprises unprepared. In that case the government took measures for helping them to survive to the end of the pandemic situation.

The sectors which have been locked down in Bulgaria are the same as the whole EU. But some of them are differed. For example, a construction business, manufacturing and some services are still working. Bulgarians really like to go on restaurants, pubs and so on. That is why many people are involved in this business. Last figures show that more than 300 000 people are unemployed. It means that around $13 \%$ of the population in employed age 
are unemployed in Bulgaria. According to the National Statistical Institute (NSI) in 2015, the relative share of small enterprises with up to 9 people is $92.49 \%$ and in $2016-92.46 \%$, for $2017-92.48 \%$. [2]. That is why the promlem with SMEs is current topic.

\section{Economic and labor overview in the European union from the begging of COVID-19}

In according to Eurostat business and economy: a cautious economic recovery with stable consumer prices tempered by contracting retail sales. The EU economy as a whole rebounded in Q3 2020 after an unprecedented slump caused by the coronavirus pandemic, but output remained well below pre-pandemic levels. In quarter-on-quarter terms, gross domestic product (GDP) bounced back by a record $11.5 \%$ in Q3 2020 after a steep drop of $11.4 \%$ in Q2 2020. The largest quarter-on-quarter increases in GDP were recorded in France $(18.7 \%)$, Spain $(16.4 \%)$ and Italy $(15.9 \%)$, while the smallest were in Greece $(2.3 \%)$, Finland $(3.2 \%)$, Estonia $(3.3 \%)$ and Bulgaria 3.8\%. In year-on-year terms, EU GDP decreased by $4.2 \%$ in Q3 2020, with differences across Member States.

In the EU, turnover in services jumped quarter-on quarter by $12.3 \%$ in Q3 2020 but still decreased year-on-year by $6.3 \%$. Air transport and the tourism sector continued to be amongst the hardest hit by the ongoing pandemic. In the EU, the total number of flights tumbled year-on-year by $66.9 \%$ in December 2020 after a decline of $68.3 \%$ in November 2020. The total number of nights spent at tourists accommodation establishments dropped steeply year-on-year by $48.3 \%$ in October 2020 after a decline of $41.1 \%$ in September 2020. Across Member States, in October 2020, the highest decreases in the number of nights spent at tourists accommodation establishments were recorded in Croatia (-79.9 $\%)$, Spain $(-79.7 \%)$ and Malta $(-75.5 \%)$.

The EU's industrial production rose for a seventh successive month in November 2020 and was almost back to pre-pandemic levels, highlighting the sector's resilience to the recent pandemic restrictions. In month-on-month terms, industrial production rose by 2.3 $\%$ in November 2020 after rising $2.0 \%$ in October 2020 and $0.4 \%$ in September 2020. Across Member States, in November 2020, the month-on-month changes in industrial production ranged from $-5.1 \%$ in Portugal, $-3.5 \%$ in Belgium, $-2.6 \%$ in Croatia to 5.3 $\%$ in Denmark, $6.3 \%$ in Greece and $52.8 \%$ in Ireland. In year-on year terms, the EU's industrial production decreased by $0.4 \%$ in November 2020, after a contraction of $2.9 \%$ in October 2020. Electricity consumption in the EU decreased year-on-year by $0.4 \%$ in October 2020 after a decrease of $1.4 \%$ in September 2020.

At the EU level, construction output climbed in November 2020. Production in construction rose month-on-month by $1.2 \%$ in November 2020, following an increase of $0.7 \%$ in October 2020. Across Member States, the month-on-month changes in construction output ranged from $-4.9 \%$ in Romania, $-1.4 \%$ in Spain and $-0.9 \%$ in Belgium to $7.0 \%$ in Slovakia, $12.0 \%$ in Hungary and $12.2 \%$ in Slovenia.

EU retail sales contracted in November 2020. Retail trade decreased month-on-month by $5.0 \%$ in November 2020, after an increase of $1.4 \%$ in October 2020. Across Member States, in November 2020, the month-on-month changes in retail trade ranged from -18.0 $\%$ in France, $-15.9 \%$ in Belgium and $-11.0 \%$ in Ireland to $1.8 \%$ in Malta and Finland, $2.5 \%$ in Croatia and $2.6 \%$ in the Netherlands. In year-on-year terms, EU retail trade dropped by $2.0 \%$ in Q3 2020 after an increase of $4.1 \%$ in Q2 2020.

Consumer prices in the EU, when measured on a year-on-year basis, remained rather flat in December 2020. The EU annual inflation rate was $0.3 \%$ in December 2020, up slightly from $0.2 \%$ in November 2020. Across Member States, in December 2020, annual 
inflation ranged from $-2.4 \%$ in Greece, $-1.2 \%$ in Slovenia and $-1.0 \%$ in Ireland to 2.4 $\%$ in Czechia, $2.8 \%$ in Hungary and $3.4 \%$ in Poland.

EU exports and imports of goods to the rest of the world increased month-on-month by $1.9 \%$ and $2.1 \%$, respectively, in November 2020. Openness to trade - exports and imports to GDP ratio - stood at 91.2 \% in Q3 2020, down from 99.4 \% in Q3 2019.

Economic sentiment showed signs of recovery in December 2020 amid prospects for a vaccine roll-out. DG ECFIN's Economic Sentiment Indicator (ESI) for the EU improved month-on-month by 2.8 points to 89.5 in December 2020, almost offsetting the drop registered in November 2020. The ESI, however, remained 13.5 points below its prepandemic level in February 2020.

EU labour market showing some signs of improvements. The unemployment rate in the EU slightly declined over recent months after the peak observed in July 2020. The EU unemployment rate was $7.5 \%$ in November 2020, down slightly from $7.6 \%$ in October 2020. It was 0.3 percentage points (pp) below its peak in July 2020 and 0.9 pp above its level in November 2019. Across Member States, in November 2020, the unemployment rate ranged from $2.9 \%$ in Czechia, $3.3 \%$ in Poland and $4.0 \%$ in the Netherlands to 8.9 $\%$ in Italy, $10.4 \%$ in Lithuania and $16.4 \%$ in Spain. However, the unemployment rate is insufficient to describe labour market developments in the current circumstances.

Labour market slack in the EU, which comprises all persons of working age who have unmet needs for employment, decreased quarter-on-quarter by $0.2 \mathrm{pp}$ to $13.9 \%$ of the labour force in Q3 2020, far from offsetting an increase of $1.3 \mathrm{pp}$ in the previous quarter. Across Member States, in Q3 2020, the highest share of people with unmet demand for employment was in Spain, Greece and Italy, where it exceeded $20 \%$ of the extended labour force.

Employment edged up in Q3 2020 after a strong decline in Q2 2020. The EU employment rate for people aged 20 to 64, as measured by the EU's Labour Force Survey, increased quarter-on-quarter by $0.3 \mathrm{pp}$ to $72.4 \%$ in Q3 2020, only partially offsetting a decrease of $1.0 \mathrm{pp}$ recorded in the previous quarter. Across Member States, in Q3 2020, the highest rates were recorded in Germany and Sweden (both 80.4\%), and the Netherlands (79.7 $\%$ ), while the lowest ones were in Greece $(61.2 \%)$, Italy (62.2\%), Bulgaria $73.8 \%$ and Spain $(65.6 \%)$.

Government finances: debt and deficit rising to counter the pandemic. At the EU level, the government deficit and the government debt in relation to GDP increased substantially year-on-year in Q3 2020 due to emergency measures to counter the pandemic. The government deficit to GDP was $5.3 \%$ in Q3 2020, up from $0.6 \%$ in Q3 2019, while the government debt to GDP ratio rose to $89.8 \%$ in Q3 2020 from $79.2 \%$ in Q3 2019. Across Member States, in Q3 2020, the government deficit to GDP ratio ranged from $0.9 \%$ in Denmark, $1.0 \%$ in Spain and 1.1\% in Estonia to $9.4 \%$ in Italy, $9.5 \%$ in Belgium, $9.8 \%$ in Malta and in Bulgaria 3.8\%. [3]

The figures are showing that in the whole EU economic, financial and labor situation in not good. In the last quarter the situation is little bit better but still we can not assume that the economic is recovering. The SMEs should focus on the future using smart technologies so they are constantly monitoring the most important infrastructure roads, bridges, tunnels, railways, metro, airports, seaports, communication systems, water supply, power supply, even important buildings - for optimal resource allocation and safety[4]. Smart cities can provide formation of E-hub which typical example is the E-hub Bourgas which will provide training, support and mentoring for students and $\mathrm{PhD}$ students to help them to become entrepreneurs[5]. For SMEs the future is in grants from 
government. Investment in innovation helps reduce environmental pollution, supports the deployment of products whose production consumes less resources [6]. In tat context circular tourism can combine tourism and sustainable resource management. Its purpose is to produce goods and tourist services, while limiting the impact on the environment (including consumption and non-renewable energy).[7]. That it is why when it comes to cost reduction and sciesity of resources we think about the water. Cutting cost approach and optimization processes are a must for this new role of business management. The specific role of the management is the incorporation of using financial, nonfinancial, BI intelligence and $\mathrm{I} / \mathrm{O}$ things work together for value creation[8]. Example for using technology is the integrated GIS approach with hydraulic calculation includes the following stages: Creating a digital elevation model (DEM).[9].

When it comes to formation for modelling the conditions affecting population migration activity, 30 indicators classified into five groups are selected by the method of an integral index construction: demographic stability and public health status; education coverage; labour market and employment conditions; standard of living; economic development of the country/region [10]. Indeed migrants are cheap labor but the economic benefit of it is extremely small spent in vain. [11] To sum up SMEs are faced up to many choices when it comes to the employee and labor market.

\section{Governmental measures in Bulgarian in pandemic situation}

First measure is called 60/40.Micro and small enterprises in Bulgaria, which have registered a decrease of at least $20 \%$ in their turnover for April 2020 compared to the average monthly turnover for 2019 , will have the opportunity to receive amounts from 3,000 to 10,000 thousand BGN help. The Managing Authority of the Operational Program "Innovation and Competitiveness" 2014-2020. Support for micro and small enterprises to overcome the economic consequences of the COVID-19 pandemic '. The procedure allows the following categories of costs:

- Costs for the purchase of raw materials and supplies;

- External service costs (including overheads);

- Staff costs (incl. Remuneration costs and the costs of social security and health contributions at the expense of the employer, excluding staff costs supported under measure 60/40);

The total amount of the grant is 173 million BGN and covers all sectors of the Bulgarian economy (except for those supported by the Rural Development Program). The application will be made entirely electronically through the system Information system for management and monitoring of EU funds in Bulgaria 2020 with the maximum simplified administrative procedure. Project proposals that meet the evaluation criteria will be funded, in the order in which they are received, until the financial resources under the procedure are exhausted. The submitted project proposals for which there is no financial resource are not subject to evaluation.

The 60/40 scheme to support employment in the context of a coronavirus pandemic will be turned into an 80/20 for the tourism sector, and companies in the sector will also be able to rely on a subsidy within a minimum wage and for hiring the unemployed.

Second measure is called 80/20. The 80/20 scheme for restaurants, tourism, hotels and transport will continue to operate until March 31, 2021. "So far, BGN 602 million have been paid under the $60 / 40$ measure, about 250,000 jobs have been preserved. The workers not only kept $100 \%$ of their income, but also kept their work for more than 3 months. Under the measure, which refers to restaurants, tourism, hotels and transport - 80/20 is 
also open to self-insured persons, with a total of 1,700 employers and self-insured persons supported, "said the Minister of Social Affairs. The unemployment rate indicates that the registered unemployed to date are 226,013 people, and since the beginning of the state of emergency until now 205,528 people have found work.

Third measure is a project called "Save me". From January 2021, the changes under the project "Save me" of the Employment Agency, which provides financial compensation to employees from closed businesses, are already in force. Thus, a new way of forming the compensation for the period 01.01.2021 - 31.03.2021 is established, taking into account the current anti-epidemic measures. The main change is that for a working day of 8 hours, agreed in the main employment contract, the compensation will be 75 percent of the monthly insurance income for October 2020 for the respective position of the insured person. by the order of art. 4, para. 1, item 1 of the Social Insurance Code in the main employment contract in the economic activities for which temporary restrictions for their implementation have been introduced by an act of a state body. In the case of parttime work, the amount of compensation is determined in proportion to the agreed working time in the main employment contract, effective as of the date of the act of a state body. Fourth measure is called 80/0 then is transformed to 75/0. "Under the measure for closed businesses, 4019 applications have been submitted so far. The aid is - BGN 24 by December 31. Measure $80 / 0$ is envisaged to be changed to $75 / 0-75 \%$ of the insurance income of the employees. From 1 to 31 In January, this will be the benefit that people will receive. More than 32,000 parents of children in online education have applied for targeted assistance. The measure was available in January. For a whole month, they will receive one minimum wage, respectively proportionally for each week in which the child was in distance learning. "Under the measure for hotels and restaurants 80 out of 20 1,700 employers are supported.

More than 40,000 jobs are reserved in the restaurant, tourism, and transport sectors. "Unemployment is $6.7 \%$ for November 2020. 226,013 are registered unemployed until now.

All of these measures are not appropriate for Bulgarian reality. Most of the businesses and employee could not apply them. The reasons were hidden in the following specific problems:

- Employers who were closed could not use the measure 60/40 because of a lack of fresh money

- Employers did social expenses to their employee on the minimum salary for the country and they got less money.

- The government pay amounts in delay to the employee in December 2020 and January 2021.

- SMEs in Bulgaria are too small for overcoming the crisis like this. That is why they prefer stop working.

In order to develop the regional economy, the most important requirements for the localization of such free (special) zones in accordance with world standards are:

- political and economic stability in the region, accompanied by a concept of economic development and planning;

- good construction of the transport system and communications, proximity to a railway and communication center of national importance;

- environmentally friendly, environmentally friendly, high standard of physical planning;

- reliable infrastructure for all seasons during the year - transport, water, energy; 
- market access - preferential access to important markets with a major advantage;

- developed financial and banking infrastructure with prerequisites for servicing in the field of electronics and engineering;

- a required labor force, a low labor cost, a production qualification that essentially determines the type of industry that could be developed in the area;

- the existence of an existing industry with a well-developed production infrastructure and a plant economy, - a good organization of the zone and general coordination,

- prerequisites for the development of light industry in the presence of traditions and highly qualified personnel, which is a prerequisite for high quality of production and competitiveness.[12]

\section{CONCLUSION}

In this pandemic situation is very hard both EU and member states to develop new businesses. Definitely the economic situation is worse in the whole EU. The market expenditure in that time is hard for new stocks and manufacture products. The Bulgarian situation is very complex because of fresh money lack. That is why most SMEs which are family business are closed and some of them will be not opened again. The problems are both governmental and business owners. The governmental problems can be summed up in not appropriate measures which were not done in the right time. First, when the business was closed you can not expect that it will have $40 \%$ to cover the tax and social expenses. Second, freelancer professionals are missing from all of these measures. Third, people with family could not survive by $24 \mathrm{BGN}$ which is around 13 euro per working day. It means that this money will be given only for the working days in the month.

The business measures have the following type:

- SMEs are very small and most of them are family businesses. It means that the whole family is in a risk.

- SMEs do not have reserves for any unpredicted situation.

- There are not options for fresh cash.

The employee measures are locked only in lending money without interest. These amounts must be paid in the next a few years.

Bulgarian companies have little experience with investing in scientific and technical laboratories and centers. That is why the business challenge in Bulgaria is the investment and the assessment of the intellectual capital [13]. Not only labor risk but also environmental risks should me marked. In these days we are faced to many risks like flood, Earthquakes, rains and etc. Flood risk assessment gives an opportunity to the central and local authorities, business, NGO's and the general public to reach a common understanding of the flood risk which they face as a community and to promote the debate on priority measures for its prevention and reduction. [14].

Summarizing all problems and measures mean that the people will choose to move in other countries and some businesses will not be opened anymore. Future questions for discussions can be related to the risk assessment of environmental disasters and the impact to the SMEs on a regional level. To improve the accuracy of the risk assessment it is also necessary to use additional documented local information related to the applied risk mitigation measures as well as the existing emergency response plans in case of flooding. In this sense, the accuracy of the risk assessment depends largely on the knowledge and experience of local stakeholders (local authorities, residents, NGOs, businesses,etc.).[15] 


\section{REFERENCES}

[1] SMALL AND MEDIUM ENTERPRISES (SMES) FINANCE

https://www.worldbank.org/en/topic/smefinance [accessed Feb 11 2021].

[2] Katsarski N. ECONOMIC CONVERGENCE IN THE CONTEXT OF OVERCOMING THE INTRA-REGIONAL DISPARTIES IN BULGARIA August 2019 DOI: 10.18509/GBP.2019.29 Conference: 5th INTERNATIONAL SCIENTIFIC CONFERENCE GEOBALCANICA 2019 Available https://www.researchgate.net/publication/335576959_ECONOMIC_CONVERGENCE_IN_TH E_CONTEXT_OF_OVERCOMING_THE_INTRA-

REGIONAL_DISPARTIES_IN_BULGARIA [accessed Apr 21 2021].

[3] Eurostat https://ec.europa.eu/eurostat/cache/recovery-dashboard/ [accessed Feb 11 2021].

[4] Naydenov Kl. SMART CITIES - THE FUTURE OF URBAN PLANNING August 2018 DOI: 10.5593/sgemsocial2018/5.2/S19.025 Conference: 5th SGEM International Multidisciplinary Scientific Conferences on SOCIAL SCIENCES and ARTS SGEM2018 Available from: https://www.researchgate.net/publication/329929803_SMART_CITIES_-

_THE_FUTURE_OF_URBAN_PLANNING [accessed Apr 20 2021].

[5] Atanasova A. ENTREPRENEURSHIP IN SMART CITY BOURGAS 6 TH INTERNATONAL SCIENTIFIC CONFERNCE GEOBALCANICA 2020 DOI: http://dx.doi.org/10.18509/GBP.2020.39 12-14 May, 2020 Ohrid, North Macedonia ISSN 18577636 Available from: http://geobalcanica.org/wp-content/uploads/GBP/2020/GBP.2020.39.pdf

[accessed Apr 20 2021].

[6] Ivanov M. THE CIRCULAR ECONOMY AS AN ENGINE FOR REGIONAL AND URBAN DEVELOPMENT - THE NEW PARADIGM OF THE 21ST CENTURY 6 TH INTERNATONAL SCIENTIFIC CONFERNCE GEOBALCANICA 2020 DOI: http://dx.doi.org/10.18509/GBP.2020.75 12-14 May, 2020 Ohrid, North Macedonia ISSN 18577636

[7] Naydenov Kl. CIRCULAR TOURISM AS A KEY FOR ECO-INNOVATIONS IN CIRCULAR ECONOMY BASED ON SUSTAINABLE DEVELOPMENT. June 2018 DOI: 10.5593/sgem2018/5.3/S28.017 Conference: 18th International Multidisciplinary Scientific GeoConference SGEM2018 Project: Tourism

Available

from: https://www.researchgate.net/publication/328727840_CIRCULAR_TOURISM_AS_A_KEY_F OR_ECO-

INNOVATIONS_IN_CIRCULAR_ECONOMY_BASED_ON_SUSTAINABLE_DEVELOPM ENT [accessed Apr 20 2021].

[8] Katsarski N. INTEGRATED BUSINESS MANAGEMENT IN RELATION TO WATER ECOSYSTEM Knowledge International Journal 38.3(2020):595 - 599 Available from: https://www.researchgate.net/publication/350099049_INTEGRATED_BUSINESS_MANAGE MENT_IN_RELATION_TO_WATER_ECOSYSTEM [accessed Apr 21 2021].

[9] Zlatunova D. GIS APPROACH FOR CALCULATING MAXIMUM RUNOFF: A CASE STUDY IN BULGARIA May 2020 Conference: 6th INTERNATIONAL SCIENTIFIC CONFERENCE GEOBALCANICA 2020 DOI: 10.18509/GBP.2020.86 Available from: https://www.researchgate.net/publication/341745260_GIS_APPROACH_FOR_CALCULATIN G_MAXIMUM_RUNOFF_A_CASE_STUDY_IN_BULGARIA [accessed Apr 21 2021].

[10] Levytska Ol. Mulska Ol. and others Modelling the Conditions Affecting Population Migration Activity in the Eastern European Region: The Case of Ukraine May 2020 TEM Journal 9(2):507-514 DOI: 10.18421/TEM92-12 License CC BY-NC-ND Available from: https://www.researchgate.net/publication/341805757_Modelling_the_Conditions_Affecting_Po 
pulation_Migration_Activity_in_the_Eastern_European_Region_The_Case_of_Ukraine [accessed Apr 21 2021].

[11] Traykov T. Particularities of migration activities in the 21 st century. August 2017 DOI: 10.5593/sgemsocial2017/41/S15.005 Conference: Human geography; Media and communications; Information and library science; Demography and women's studies. p. 35-42, At: Albena, Bulgaria.

Available from: (PDF) Particularities of migration activities in the 21 st century. (researchgate.net) [accessed Apr 20 2021].

[12] Naydenov Kl., THE ROLE OF FREE ECONOMIC ZONES FOR THE DEVELOPMENT OF THE REGIONAL ECONOMY. August 2018 DOI:10.5593/sgemsocial2018/5.2/S20.069 Conference: 5th SGEM International Multidisciplinary Scientific Conferences on SOCIAL SCIENCES and ARTS SGEM2018 Available from: https://www.researchgate.net/publication/329925411_THE_ROLE_OF_FREE_ECONOMIC_Z ONES_FOR_THE_DEVELOPMENT_OF_THE_REGIONAL_ECONOMY [accessed Apr 21 2021].

[13] Katsarski N. THE NEW BUSINESS THINKING WITH INTEGRATED REPORTING June 2019 DOI: 10.5593/sgem2019/5.3/S21.108 Conference: 19th SGEM International Multidisciplinary Scientific GeoConference EXPO Proceedings Available from: https://www.researchgate.net/publication/334758473_THE_NEW_BUSINESS_THINKING_W ITH_INTEGRATED_REPORTING [accessed Apr 21 2021].

[14] Zlatunova D. INTEGRATING FLOOD RISK ASSESSMENT INTO MANAGEMENT PRACTICE (CASE STUDY IN BULGARIA). September 2018 DOI:10.18509/GBP.2018.55 Conference: 4th INTERNATIONAL SCIENTIFIC CONFERENCE GEOBALCANICA 201 Available from: https://www.researchgate.net/publication/327849709_INTEGRATING_FLOOD_RISK_ASSES SMENT_INTO_MANAGEMENT_PRACTICE_CASE_STUDY_IN_BULGARIA [accessed Feb 12 2021].

[15] Zlatunova D. INTEGRATING FLOOD RISK ASSESSMENT INTO MANAGEMENT PRACTICE (CASE STUDY IN BULGARIA). September 2018 DOI:10.18509/GBP.2018.55 Conference: 4th INTERNATIONAL SCIENTIFIC CONFERENCE GEOBALCANICA 201 Available from: https://www.researchgate.net/publication/327849709_INTEGRATING_FLOOD_RISK_ASSES SMENT_INTO_MANAGEMENT_PRACTICE_CASE_STUDY_IN_BULGARIA [accessed Feb 12 2021].] 